\title{
Impact of IT Multisourcing on vendor opportunistic behaviour - A research framework
}

\section{Bhavya Peapully Shroff}

Information Systems area

Indian Institute of Management Bangalore

Bangalore, Karnataka

India

Email: bhavya.ps@iimb.ac.in

\section{Rajendra K. Bandi}

Information Systems area

Indian Institute of Management Bangalore

Bangalore, Karnataka

India

Email: rbandi@iimb.ac.in

\section{Abstract}

IT Multisourcing (ITM), the provision of IT services by multiple interdependent vendors to a single client, is widely prevalent now. ITM, in principle, is believed to mitigate both strategic and operational risks of IT outsourcing for client organizations. Yet there is limited research which systematically investigates the effects of ITM on different forms of risk. This paper develops a theoretical framework to understand the implications of ITM for the specific risk of vendor opportunistic behaviour, classified as a 'strategic risk' of outsourcing. The fundamental attributes of ITM are identified and mechanisms through which they influence vendor opportunistic behaviour are explained. The advantages and limitations of the framework are discussed, and future research directions are laid out.

Keywords IT Multisourcing, IT outsourcing risks, risk mitigation, opportunistic behaviour 


\section{Introduction}

IT Multisourcing (ITM) is emerging as a prominent form of IT outsourcing (ITO), with several organizations moving from a single-vendor outsourcing arrangement to ITM (Everest 2018). IT Multisourcing refers to the provisioning of IT services to a client by multiple IT vendors where interdependencies exist between vendors with respect to their tasks and service delivery for the client (Bapna et al. 2010). ITM is perceived to offer various benefits such as access to specialized vendors and technologies, providing greater flexibility, and mitigation of strategic and operational risks of ITO for the client organizations (Bapna et al. 2010; Cohen and Young 2006). Researchers argue that the high perception of 'vulnerability' to cost escalation and inflexible services (Cross 1995), hidden service costs and lock-in experienced by a client in single-vendor settings of huge contract size (Aubert et al. 2005) has prompted client organizations to look for sourcing strategies involving more than one vendor. In principle ITM mitigates the strategic and operational risks of ITO (Bapna et al. 2010; Cohen and Young 2006). Strategic risks result from the deliberate opportunistic behaviour of the vendors, whereas operational risks arise from reasons other than deliberate behaviour such as complexity of operations, geographic separation between client and vendors and coordination difficulties (Aron et al. 2005). While there is evidence supporting the use of ITM for risk-mitigation by client organizations (Bahli and Rivard 2013; Currie 1998; Wiener and Saunders 2014), not much is known about the underlying mechanisms through which ITM mitigates risks. Also, there are contending arguments that ITM introduces some risks (Wiener and Saunders 2014), that it may not mitigate all forms of strategic risks (Aron et al. 2005; Clemons and Hitt 2004), and that it even aggravates operational risks (Su and Levina 2011). This calls for a need for further scrutiny of the implications of ITM on various risks of ITO and systematically evaluate the impacts of ITM for risks. Such an analysis is very important for organizations that are increasingly adopting ITM, to avoid the pitfalls of ITM as well as reap the intended benefits. The key objective of the current research is to get a more nuanced understanding of the implications of ITM for the risks of outsourcing by identifying the underlying mechanisms through which ITM impacts specific risks.

Su and Levina (2011) present a theoretical framework that explains the implications of ITM for strategic and operational risks of outsourcing and considers the role of the vendor-base. The risk implications of other important aspects of ITM such as vendor-interdependence, embeddedness and network governance, task visibility, vendor-client relationships, have been largely unexplored in ITM literature. Moreover IT Multisourcing exists in several forms involving different choices in vendor grouping, work division, distribution of hierarchy and authority, that can have different implications for various outcomes such as risk management (Cullen et al. 2005) and learning (Koo et al. 2017). However, from a risk perspective, literature has not considered the choices pertaining to the ITM forms in investigating the risk-mitigation impacts of ITM. Also, the conceptualization of the ITM attributes is fragmented with various studies using different sets of criteria to describe ITM making it difficult to get a comprehensive understanding of the ITM attributes or their implications for risks or any other outcomes. For instance, ITM has been described with respect to the size of vendor base and depth of client-vendor relationships (Su and Levina 2011), interaction among client and vendors being direct or mediated (Wiener and Saunders 2014), contracting between client and multiple vendors being direct or through subcontracting (Koo et al. 2017) and choices in handling of service integration and management responsibilities (Goldberg et al. 2014). Such variety hinders a cumulative understanding of ITM and comparison of findings across studies. Any comparison across these different choices of an ITO arrangement requires a sound understanding of the differences in the overall structure and intent of IT outsourcing arrangements (Cullen et al. 2005). Lack of this understanding could drive an assumption of uniform impacts of all outsourcing forms on the outcomes of interest, subsequently leading to contradictory findings (Dibbern et al. 2004). Given the contradictory views expressed about ITM's riskmitigation effect, it is important to have a more comprehensive view of the fundamental attributes of ITM to better understand the implications of ITM for risks.

In this paper we address the two limitations identified from literature: (a) Lack of systematic inquiry into the implications of ITM for outsourcing risks, along with contending views on risk implications of ITM, and (b) fragmented conceptualization of ITM deterring the establishment of definite impacts of ITM on outsourcing risks. In particular, the paper focuses on the risk of vendor opportunistic behaviour, which is classified as 'strategic risk' of outsourcing for the client (Aron et al. 2005; Su and Levina 2011). Vendor opportunistic behaviour remains a key concern in ITO practice and is relevant across various IT services such as IT infrastructure (e.g., Chang et al. (2017)) and software development (e.g., Gefen et al. (2008)). Recent studies highlight various 'vendor risks' for clients including other behavioural risks arising in multisourcing such as vendors blaming each other for failures, scope for collusive activities of vendors and free-riding, which are yet to be fully understood (Bunker et al. 2016; de Sá-Soares et al. 
2014; Wiener and Saunders 2014). Several forms of vendor opportunistic behaviour exist, and the mechanisms focussed to mitigate one form may be ineffective for the other forms (Clemons and Hitt 2004; Mathew and Chen 2013). It is important to understand what forms of opportunism are mitigated or aggravated in ITM settings, which will be useful in identifying the trade-offs in ITM. In this regard, the research question addressed by the current study is: How does IT Multisourcing influence vendor opportunism risks? The key contribution of the paper is a framework that describes the influence of various ITM attributes on vendor opportunistic behaviour. The fundamental attributes of ITM, mechanisms and various forms of vendor opportunistic behaviour are identified from ITO, ITM and other studies. The influences of various ITM attributes on vendor opportunistic behaviour are explained in the framework. This insight will be important for risk management in ITM.

\section{Literature Background}

Risk is the extent of exposure of a party (client or vendor) involved in a transaction to a chance of loss or damage (Lacity et al. 2016). Clients typically face several risks in ITO arising from vendors, the complexity of operations, technology, location and several other factors: There is significant evidence that risks can negatively impact ITO outcomes (Lacity et al. 2016). The current study will focus on one such category of risks, 'vendor opportunistic behaviour' as it is widely acknowledged as one of the major issues across several outsourced IT services. Vendor opportunism in ITO can result in significant loss for clients in the form of reworks, budget overruns, disputes, delays in service delivery to end-user, service disruptions, loss of proprietary assets and expertise to competitors and the eventual loss of competitive advantage (Clemons and Hitt 2004; Mathew and Chen 2013). Since ITM has been positioned as a risk-mitigation strategy, we investigate the effect of ITM on vendor opportunistic behaviour. Opportunism is an embedded and constitutive aspect of outsourcing and can be handled better only by understanding the constitutive elements of outsourcing engagements (Wüllenweber et al. 2008). The current study follows this approach by investigating the effects (such as mitigating, or aggravating) of specific attributes of ITM on vendor opportunistic behaviour. We first discuss the forms of vendor opportunistic behaviour and then provide a description of attributes of ITM and the mechanisms through which they influence vendor opportunism.

\subsection{Strategic risks: Opportunistic behavior in IT outsourcing}

Opportunism is a fundamental assumption of transaction cost economics (TCE). Opportunistic behaviour of partners in exchange can be defined as 'self-interest seeking with guile' which is detrimental to the others (Williamson 1975). This is a willful strategic behaviour corresponding to 'calculated efforts to mislead, distort, disagree, obfuscate, or otherwise confuse' (Williamson 1985), which includes lying, stealing and cheating (Williamson 1975, 1985). It is assumed that the economic agent knows that benefits will accrue to self by behaving opportunistically (Williamson 1975). Though it doesn't imply that most economic agents will behave opportunistically most of the time, ignoring opportunism from the analysis of organizational forms will lead to their uncritical assessment leaving out many economic problems (Williamson 1993).The notion of opportunism allows considering both ex-ante and ex-post settings, thereby subsuming under itself many economic issues or phenomena which have been defined in information economics and agency theory (Williamson 1993). In ITO research opportunism corresponds to wilful violation of contracts and relational norms (Ravindran et al. 2015). Vendor opportunistic behaviour includes shirking, misappropriation of assets, forced renegotiation or vendor holdup, vendor underinvestment and collusive behaviour of vendors (Aron et al. 2005; Lioliou and Zimmermann 2015; Loboda 2013, 2013; Mathew and Chen 2013; Su and Levina 2011; Wiener and Saunders 2014). It can be noted that these include risks from both individual vendors and the collective of vendors.

Recent studies in ITO have investigated how vendor opportunistic behaviour is mitigated in outsourced IT services in a single vendor setting (e.g., Lioliou and Zimmermann 2015; Mathew and Chen 2013). Vendor opportunism in an ITM setting goes beyond the client-vendor dyad into a network of clientvendor organizations. There is a potential for collusion of vendors when there are increased synergies and information exchange among vendors and with the client losing control over what information is exchanged among vendors (Choi et al. 2002; Wiener and Saunders 2014). Other risks can be vertical integration by vendors into client's business and competing with client, and collusive activities of vendors like price-fixing, anti-competitive conduct such as reduce competition by partitioning market which shift power and cost structure towards benefitting the vendors and lead to appropriation risks for client (Choi et al. 2002). Even though there is little empirical evidence for such risks in ITM setting, their possibility cannot be ruled out altogether. Such instances of vendor collusion have been noticed in buyer-supplier networks in manufacturing (Choi et al. 2002) wherein it could be detrimental to buyer 
firm's performance and therefore is an important concern for buyers. Another kind of opportunistic behaviour that could prevail in multi-vendor network that caters to a single client is the manipulation of client's decisions by a dominant vendor in its favour with an intention to enhance its own position relative to the other vendors (Provan 1993). Table 1 provides a summary of different forms of vendor opportunistic behaviour as identified in the ITO \& ITM literature and other studies. These forms are drawn from the theoretical perspectives of TCE, agency theory, incomplete contracts theory and powerdependence view which offer bases for identifying a variety of opportunistic behaviours and the associated drivers. Such a multi-theoretical approach has been used by several studies that have researched opportunism in a variety of settings, for instance, Aubert et al. (2005) uses TCE and agency theory in IT outsourcing; Crosno and Dahlstrom (2008) uses four theoretical perspectives namely institutional economics, resource dependence theory, relational contracting theory and behavioural perspective) in marketing, etc.

\begin{tabular}{|c|c|c|c|}
\hline $\begin{array}{l}\text { Strategic risk/ } \\
\text { opportunistic } \\
\text { behaviour }\end{array}$ & Theory & $\begin{array}{l}\text { Key } \\
\text { contributing } \\
\text { factors }\end{array}$ & Representation in Studies \\
\hline $\begin{array}{l}\text { Withholding } \\
\text { /distorting } \\
\text { information }\end{array}$ & $\begin{array}{l}\text { Agency } \\
\text { theory, } \\
\text { TCE }\end{array}$ & $\begin{array}{l}\text { Information } \\
\text { asymmetry }\end{array}$ & $\begin{array}{l}\text { Can occur any time, ex-ante or ex-post. } \\
\text { Overstating capabilities, hiding } \\
\text { information (Bahli \& Rivard 2013); } \\
\text { sometimes subsumed under 'shirking' } \\
\text { (Clemons et al. 1993) }\end{array}$ \\
\hline \multirow[t]{3}{*}{ Shirking } & \multirow[t]{3}{*}{$\begin{array}{l}\text { Agency } \\
\text { theory }\end{array}$} & \multirow[t]{3}{*}{$\begin{array}{l}\text { Low } \\
\text { observability } \\
\text { of effort } \\
\text { Low } \\
\text { verifiability of } \\
\text { output }\end{array}$} & $\begin{array}{l}\text { Underinvestment in training, equipment } \\
\text { and other facilities, lack of effort, assigning } \\
\text { under-skilled staff (Aubert et al. 1999; } \\
\text { Mathew and Chen 2013); Wilful } \\
\text { underperforming (Clemons et al 1993); }\end{array}$ \\
\hline & & & $\begin{array}{l}\text { Refraining from making noncontractual } \\
\text { specific investment; Complacence } \\
\text { reflected in its attitude of 'take-it-or-leave- } \\
\text { it' and not focusing on improving quality } \\
\text { (Wiener and Saunders 2014) }\end{array}$ \\
\hline & & & $\begin{array}{l}\text { Imperfect commitment - reneging on } \\
\text { explicit or implicit commitments, not } \\
\text { fulfilling obligations and promises (Jap } \\
\text { and Anderson 2003) }\end{array}$ \\
\hline \multirow[t]{3}{*}{ Misappropriation } & \multirow[t]{3}{*}{ TCE } & $\begin{array}{l}\text { Lock-in } \\
\text { Asymmetric } \\
\text { Dependence }\end{array}$ & $\begin{array}{l}\text { Wilful exploitation of dependence } \\
\text { (Nooteboom et al. 1997); Haggling, } \\
\text { appropriation of surplus (Ravindran et al. }\end{array}$ \\
\hline & & $\begin{array}{l}\text { Resource } \\
\text { dependence }\end{array}$ & $\begin{array}{l}\text { 2015); Poaching, intellectual property } \\
\text { issues, confidentiality breaches like } \\
\text { leaking client's proprietary information to } \\
\text { third parties, unapproved use for own } \\
\text { benefit (Clemons \& Hitt 2004; Mathew \& } \\
\text { Chen 2013) }\end{array}$ \\
\hline & & $\begin{array}{l}\text { Power } \\
\text { asymmetries } \\
\text { among } \\
\text { vendors }\end{array}$ & $\begin{array}{l}\text { Misuse of power by dominant or lead } \\
\text { vendor (Provan 1993) }\end{array}$ \\
\hline \multirow[t]{3}{*}{ Maladaptation } & \multirow[t]{3}{*}{ TCE } & $\begin{array}{l}\text { Lack/loss of } \\
\text { bargaining } \\
\text { power }\end{array}$ & $\begin{array}{l}\text { Inflexibility, refusal by vendors to adapt } \\
\text { (Wathne and Heide 2000) }\end{array}$ \\
\hline & & $\begin{array}{l}\text { Small numbers } \\
\text { bargaining }\end{array}$ & \\
\hline & & $\begin{array}{l}\text { Rigid } \\
\text { contracts, } \\
\text { incomplete } \\
\text { specifications }\end{array}$ & \\
\hline
\end{tabular}




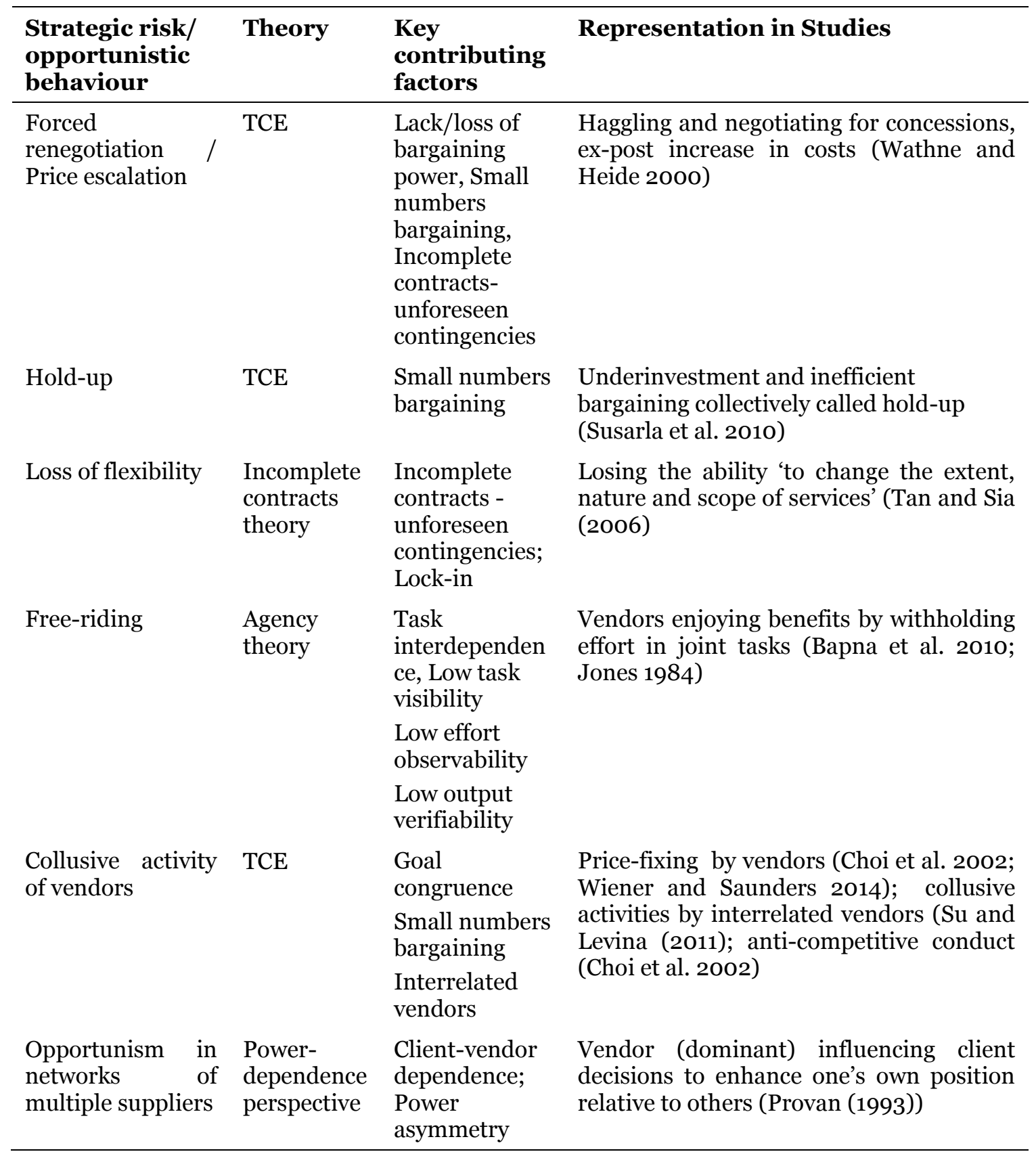

Table 1. Vendor Opportunistic Behaviour: Forms and Contributing Factors

\section{Role of IT Multisourcing in mitigating Vendor Opportunism}

Risk-mitigation mechanisms help reduce the likelihood of occurrence of potential negative scenarios by reducing the intensity of risks or preventing the risks altogether (Bahli and Rivard 2003, 2013). In this regard, ITO literature has investigated the effectiveness of a variety of risk-mitigation mechanisms such as contractual safeguards, network embeddedness, relational mechanisms, psychological contract, social capital, monitoring and control in curbing opportunism in a dyadic setting (Chang et al. 2017; Lacity et al. 2009; Mathew and Chen 2013; Ravindran et al. 2015). Though a variety of risk-mitigation mechanisms have been discussed in ITO literature, ITM is essentially different as it moves beyond a dyad into a network of client-vendor organizations. ITM is based on the idea that competition between multiple vendors can be used to drive cost reductions for client (Porter 1985) thereby reducing the opportunistic rent appropriation by any one vendor (strategic risk) (Aron et al. 2005). It provides an opportunity to reduce client's dependency and vulnerability with respect to any single vendor without having to reduce the overall degree of outsourcing (Currie and Willcocks 1998; Levina and Su 2008). As noted earlier, risk implications of ITM is an understudied area and the only framework for 
understanding the impact of ITM on strategic risks, by Su and Levina (2011), focuses on two dimensions of vendor-base (breadth and depth) while omitting other constituent elements of ITM. In the next section the constituent elements of ITM are identified from literature and the key mechanisms such as vendor competition, bargaining power, mutual monitoring and information exchange, which influence vendor opportunistic behaviour are explained. The focus of the paper is on those attributes of ITM that have a bearing on vendor opportunism. We identify these attributes as pertaining to strategy, division of work, network structure and governance.

\subsection{Strategy}

Sourcing strategy reflects the choices made about IT services such as how they are sourced (from internal or external vendors), sourcing location, degree of outsourcing and pricing. In ITM additional choices include the number of vendors and their skillsets, and tiering of vendors according to their strategic importance for the client. In ITM, the use of multiple vendors induces vendor competition. It can enhance the power position of client with respect to the dominating vendor through engagement with multiple vendors who are alternative sources for acquiring resources (Huang et al. 2004). In outsourcing of IT services that require significant customization, the dependency on vendor is even more when it involves tacit knowledge and relationship specific investments. Overlap in vendor areas of expertise is found to be useful in inducing constant competition among vendors while also reducing the dependence of client on any single vendor (Wiener and Saunders 2014).

\subsubsection{Bargaining power as mechanism}

Bargaining power is defined with respect to contractual relationships as 'the ability of one party to a contract to be able to influence the terms and conditions of that contract or subsequent contracts in its own favour' (Argyres and Liebeskind 1999). From a TCE perspective ITM acts as a safeguard in situations where bargaining power is skewed towards vendors, and curbs the vendor opportunistic behaviours of holdup and thereby preventing cost escalations (Bahli and Rivard 2013). Vendor-base breadth or 'number of vendors' (Su and Levina 2011), has significant positive influence on the relative bargaining power of client (restricting vendor bargaining power) which in turn deters vendor opportunistic behaviours of ex-post renegotiation and vendor inflexibility.

\subsubsection{Vendor competition as mechanism}

Competition refers to a situation wherein several actors in a market produce and market similar products or services, and firms compete to achieve above-average profits and derive competitive advantage (Osarenkhoe 2010). Having more than one vendor leads to a more competitive environment for vendors. Price competition may be witnessed during bidding for client projects when vendors compete in acquiring new business opportunities from client. It leads to performance benefits in the form of lower IT service costs and improved quality (Wiener and Saunders 2014). It also safeguards against ex post forced renegotiations and price escalations when switching costs are low (Su and Levina 2011). Reduced contract size and duration along with frequent bidding will lead to ongoing vendor competition (Wiener and Saunders 2014). The number of vendors and the overlap in vendor expertise will have significant positive influence on the competition between vendors which deters ex post vendor opportunistic behaviour (Wiener and Saunders 2014) while also lowering the costs of negotiation for client, improving IT service quality and flexibility and reducing vendor dependency (Aubert et al. 2016).

\subsection{Division of Work}

By dividing tasks among multiple vendors ITM brings transparency in the activities which were hitherto covered under a single vendor, by making tasks more visible and allowing for scrutiny by client (Wiener and Saunders 2014). On the other hand, vendors with interdependent tasks will be able to monitor one another even when their outputs are not measurable. In either way, shirking by vendors will be curbed. But such mitigating effects depend on whether or not tasks are divided in a way to increase observability of effort as well as outputs. The task interdependence between vendors is considered a key differentiating feature of ITM (Bapna et al. 2010).

\subsubsection{Task interdependence}

Task interdependence can be of three types that differ in terms of task relationships- pooled, sequential, reciprocal (Thompson 1967). Pooled interdependence among vendors in an ITM setting corresponds to 'part-whole' relationship between tasks carried out by vendors wherein the contributions of each vendor are discrete and the interactions between tasks may not be direct but rather each task has a role to play in contributing to the end-to-end service delivery to clients. In sequential interdependence, the output of one vendor's task becomes input for another vendor in unidirectional way. In reciprocal 
interdependence vendor's activities become inputs for each other's activities, which requires wider fit between their activities and extensive information exchange.

Varying levels of task interdependence are associated with varying levels of task visibility and information exchange for vendors and client (Jones 1984). Pooled, sequential and reciprocal interdependence correspond to increasing levels of interdependence. Two main risks that are associated with high task interdependence between vendors are shirking (underinvestment of effort) and freeriding (gaining rewards or consuming output without contributing to it) (Jones 1984). In pooled interdependence minimal communication is required between vendors and yet the effort of vendors is discrete and can be monitored. Sequential interdependence would need vendor interaction since inputs/outputs ensuing from one vendor flow to another. In reciprocal interdependence the effort of vendors is less discrete and may be difficult to measure, but observable to the other dependent vendors. Mutual monitoring and high information exchange are possible in reciprocal interdependence. Even when performance evaluation is not possible, shirking and free-riding can be curbed depending on how tasks are grouped to induce transparency. However, when joint effort is needed, high interdependence could lead to free-riding problems (Jones 1984). When the contributions of individual vendor with respect to the final product cannot be distinguished from group effort, it leads to the problem of freeriding. Therefore reciprocal interdependence could lead to free-riding and shirking, and pooled interdependence may be effective to curb shirking since it makes each vendor's distinct contribution more visible.

\subsection{Network Structure}

\subsubsection{Effects of Vendor Embeddedness}

Another key characteristic of ITM is that it comprises of many client-vendor dyads forming a network of relationships among client and vendors. In such a network where all vendors are focussed on catering to a single client, any client-vendor relationship is 'embedded' in the lager network, and such embeddedness has the potential to limit opportunistic behaviour (Granovetter 1985). More specifically in buyer-supplier networks the embeddedness of vendor can occur in two ways - vendor's dependence on client and connectedness of vendor with other vendors (Provan 1993). The key argument in this regard, is that vendor embeddedness is high when both these are high thereby directly curbing any opportunistic behaviour of the vendors. Networks can allow high exchange of information (Ravindran et al 2015), thereby any opportunistic behaviour of vendors will be known across the network members. Under high dependence of vendors on the network and when their actions affect the entire network it creates 'outcome interdependence' among vendors and they refrain from opportunistic behaviour (Provan 1993). The position of vendor in the network will provide informational and reputational advantages (Kim 2014) which will be lost if vendor resorts to opportunistic behaviour. The network provides social monitoring benefits (Kim 2014) and flow of information about markets and vendor behaviour among the members of the network (Ravindran et al. 2015). Therefore, network acts as a safeguard against all forms of opportunistic behaviour caused by lack of observability of vendor effort, information asymmetry and violations of formal and informal norms. Vendor is likely to refrain from behaving opportunistically as this could lead to long-term repercussions in the form of exclusion from network and future deals, along with reputation damage (Provan 1993). But such high information exchange and the synergies that arise therein may prompt vendors to undertake collusive activities such as price fixing (Su and Levina 2011).

\subsection{Governance Structure}

The choice made in governing the network of client-vendors can also influence vendor opportunistic behaviour. Current literature loosely refers to two ways of organizing ITM - 'direct' and 'mediated' models. In a direct model the client directly interfaces with multiple vendors whereas in a mediated model the client chooses a vendor to act as a single point of contact to coordinate with other vendors (Bapna et al. 2010; Wiener and Saunders 2014). In this study we consider two broad options of direct and mediated ITM models, depending on whether a client, or a vendor (lead vendor) chosen by client, handles key governance activities of monitoring, implementation of standards and procedures, risk audit. A lead vendor provides services to client much like other vendors, but additionally coordinates governance activities. It influences the information flow between client and vendors as well as among vendors. When a lead vendor handles governance activities, there is a chance of the vendor resorting to manipulation of client decisions favouring oneself (Provan 1993). ITM research in this area of mediated models is scarce. In the context of ITM and ITO it refers to fostering overall coordination of the ITM arrangement by acting as a bridge between vendors and buyer, handling dispute resolution, monitoring and implementing standards and procedures. However, lead vendor doesn't have direct contracts with 
other vendors, so the power of lead vendor mainly comes by being more closely associated with the client, controlling information flow and from holding high competencies, which are very essential for intermediaries (Mahnke et al. 2008). Different governance structures are likely to bestow different levels of power on client and vendors (Provan and Kenis 2008) which in turn could lead to different influences on the behaviour of network members as well as exert influence on the decisions of network members.

\subsection{Summary}

We have identified various ITM attributes corresponding to the ITM sourcing strategy, work division, network of client-vendors and governance of the network and provide a more comprehensive and generalized view of the constituent elements of ITM. While describing these attributes we have also identified their association with different mechanisms which in turn affect vendor opportunistic behaviour. Our analysis has revealed the dual effects i.e., mitigate and induce/aggravate, of ITM attributes on vendor opportunism risks. The findings are synthesized and presented as a research framework in the following section.

\section{Research Framework}

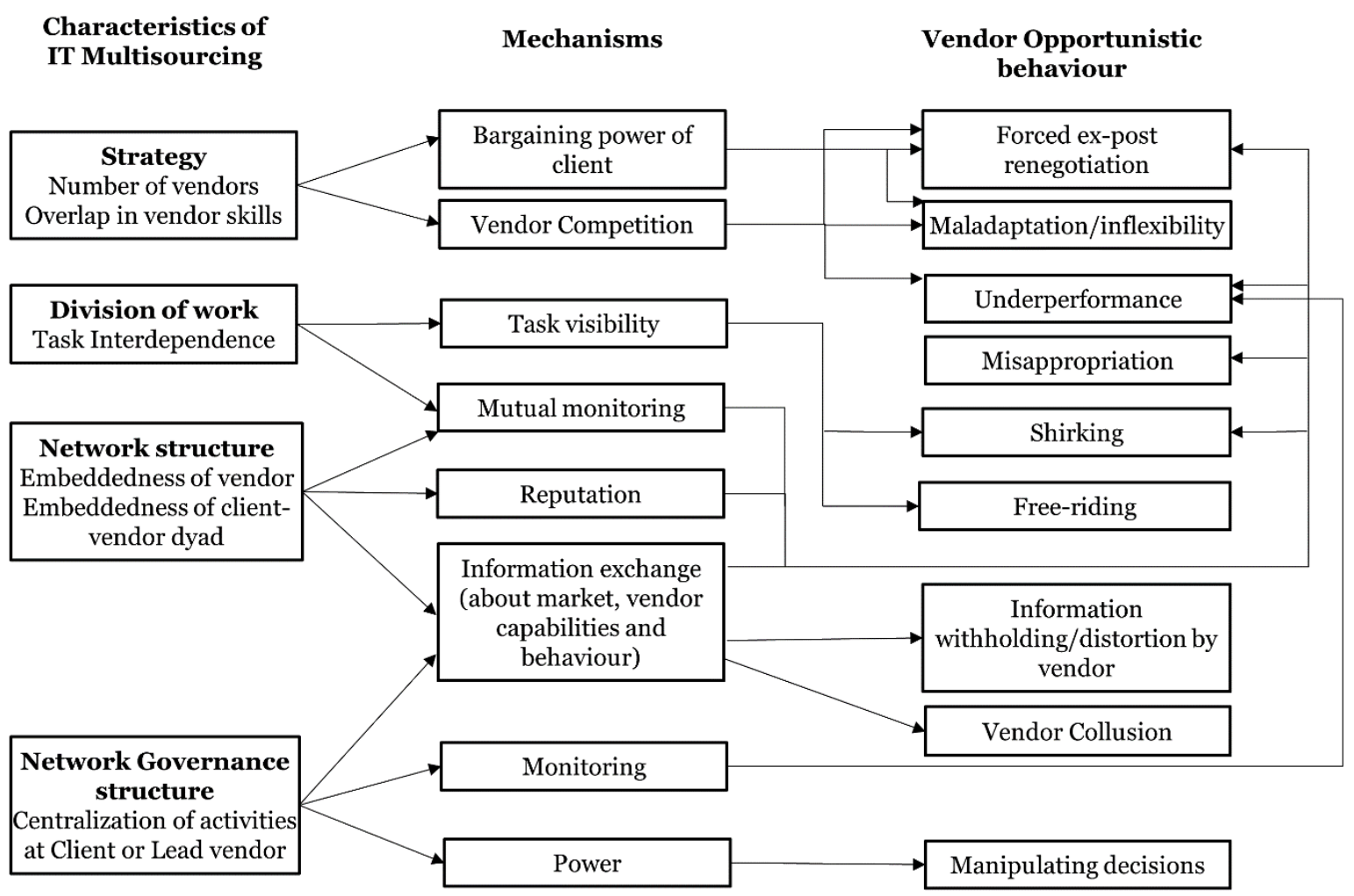

Figure 1: Research framework: Explaining the implications of ITM for vendor opportunistic behaviour

Literature on sourcing risks, in general, has extensively studied risk-mitigation mechanisms (Lacity et al. 2009) and qualitatively compared the risk-benefit implications of various forms of ITO (Angst et al. 2017; Currie and Willcocks 1998). But the effect of specific sourcing forms on risk mitigation has received less attention (Heide et al. 2014). Similar is the case of ITM where there is a lack of systematic analysis of the risk-mitigation mechanisms associated with it. By focussing on ITM attributes we have highlighted the multiple ways in which ITM can mitigate or induce vendor opportunistic behaviour. ITM improves the bargaining power of clients relative to vendors in asymmetric power situations (Bahli and Rivard 2013; Huang et al. 2004), induces competition among vendors (Wiener and Saunders 2014), can offer mechanisms of reputation and mutual monitoring by vendors, can provide information exchange conduits owing to its network characteristics, all of which act as safeguards against various forms of vendor opportunistic behaviour. Certain features of ITM, though, may lead to vendor opportunistic behaviours of free-riding, shirking and vendor collusion. Figure 1 presents the research framework summarizing the key characteristics of ITM attributes, their influence on risk mitigating mechanisms and how they impact specific types of vendor opportunistic behaviour.

The framework shows that there are many-to-many relationships between ITM attributes and 
mechanisms and between mechanisms and forms of vendor opportunistic behaviour. While the number of vendors and overlap in their skills directly influence vendor competition, information exchange between vendors is influenced by the structures of task, network and governance. In cases where direct and extensive monitoring by clients is not feasible, these various structures in ITM enable mutual monitoring among vendors and information exchange both of which are crucial to curb several forms of opportunistic behaviour of vendors. However, it is also observed that some ITM attributes which are useful in curbing some forms of opportunism could aggravate other forms of vendor opportunism. The framework therefore presents the trade-offs involved with each of the ITM attributes.

\section{Discussion}

The framework presented several features of ITM that were hitherto unexamined in the context of mitigating vendor opportunistic behaviour and it can be used for setting a research agenda for ITM's impacts on vendor opportunistic behaviour. Many ITM attributes have been found to be underresearched in terms of their implications for vendor opportunism. The dual effects of various attributes in terms of mitigating and inducing various forms of vendor opportunism are to be clearly understood in order to make better choices for ITM. For instance, the effects of interdependence of vendors determine the extent of cooperation and coordination among vendors and yet such increased coordination through increased information exchange may potentially lead to vendor collusion. It can also expose vendors to input and output risks from other vendors (Bapna et al. 2010).This leads us to the question of the extent of desirability of vendor interdependence in ITM and how can this be managed to safeguard client and vendors against opportunism. Embeddedness effects in ITM are largely unexplored. With respect to governance a key question that remains to be addressed is-What is the effect on vendor opportunistic behaviour when a client is directly governing them or when governance activities are delegated to a vendor? The implications of power of buyers and lead vendor in controlling vendor opportunistic behaviour is an uncharted domain in ITM literature. Whether certain work division choices promote task visibility better than others, is to be studied in ITM. Although interdependence has been discussed from both the task design and network structure perspective and both views appear to have the potential to curb risks of opportunistic behaviour, the connection between the two is yet to be investigated in ITM setting. It requires further investigation to understand whether task interdependence is essential for forming ties between vendors since ITMs are often characterized by short contract durations, and if network structure and task structure can independently be effective safeguards in ITM settings. While an attempt has been made to include a comprehensive list of opportunism forms and ITM attributes, there are several concepts which couldn't be taken up in this study such as goal congruence of vendors, multiple valences of vendor-vendor relationships, to name a few. Setting individual and overall goals for vendors is also a key aspect of organizing ITM. In interorganizational setting goal incongruence often leads to issues of non-commitment and non-cooperation. How individual and collective goals of vendors are set and how they influence opportunistic behaviour of vendors such as free-riding and shirking are to be studied in ITM. Several other such concepts related to ITM may be added to the framework when studying in depth the implications of a particular set of ITM attributes for risk. While the individual relationships between ITM features and mechanisms have been described in the framework, the interaction effects of these various ITM features have not been addressed in the framework. This is also an area open to research in ITM. For instance, when task interdependencies exist among vendors along with competition, it could lead to adverse effects by hampering vendor cooperation. More investigation is needed on the specific interactions among competition, interdependence and social ties among vendors and ways to balance these in order to achieve risk-mitigation.

The dual effects of ITM attributes call for research on which configuration of ITM attributes will provide optimal risk-mitigation. This framework could be used to further investigate the appropriate controls to be used without incurring huge costs to curb various risks that arise in ITM settings from both individual vendors and the collective of vendors. Problems of commitment that arise from incentive misalignment in vendors also pose risks to client. Though not considered in this study, it has been identified as a potential area of research (Bapna et al. 2010). Future studies could also use concepts from this framework to focus on other forms of risks such as loss of flexibility, operational and security risk; and other outcomes of interest.

\section{Conclusion}

The study takes a risk perspective of ITM and explains theoretically how ITM offers multiple ways to safeguard against some forms of vendor opportunistic behaviour while inducing some others. By using 
a more comprehensive conceptualization of the constituent elements of ITM the framework offers a basis for developing a common ground to consolidate findings across seemingly different ITM arrangements. Thus it addresses the limitation of 'fragmented conceptualization' of ITM. It also offers nuances of differing implications of a given ITM attribute on various forms of vendor opportunistic behaviour. It thereby presents a more contrasting view of ITM than earlier studies and offers explanation for the contradictory views expressed about risk implications of ITM. Thus we have addressed both the limitations that we have identified earlier with ITM literature. This research can be extended to consider the operationalization of various concepts discussed in the framework and carry out multiple empirical studies focusing on risks or other outcomes of interest. Such studies will benefit from using a conceptualization of different ITM models in terms of their underlying attributes so that their findings can be comparable. Such studies can use these ITM attributes to study even other outcomes of interest like value. Our future empirical study will draw from this research framework and build a more nuanced empirical research model with the specifics of ITM governance and its implications for vendor opportunism.

\section{References}

Angst, C. M., Wowak, K. D., Handley, S. M., and Kelley, K. 2017. “Antecedents of Information Systems Sourcing Strategies in US hospitals: A Longitundinal Study.," MIS Quarterly (41:4), pp 1129-1152.

Argyres, N. S., and Liebeskind, J. P. 1999. "Contractual commitments, bargaining power, and governance inseparability: Incorporating history into transaction cost theory," Academy of management review (24:1), pp. 49-63.

Aron, R., Clemons, E. K., and Reddi, S. 2005. "Just right outsourcing: understanding and managing risk," Journal of Management Information Systems (22:2), pp. 37-55.

Aubert, B. A., Dussault, S., Patry, M., and Rivard, S. 1999. "Managing the risk of IT outsourcing," in Systems Sciences, 1999. Proceedings of the 32nd Annual Hawaii International Conference on System Sciences, , p. 10-pp.

Aubert, B. A., Patry, M., and Rivard, S. 2005. "A framework for information technology outsourcing risk management," ACM SIGMIS Database : the DATABASE for Advances in Information Systems, 36(4), pp.9-28. (36:4), pp. 9-28.

Aubert, B. A., Saunders, C., Wiener, M., Denk, R., and Wolfermann, T. 2016. "How adidas Realized Benefits from a Contrary IT Multisourcing Strategy.," MIS Quarterly Executive (15:3).

Bahli, B., and Rivard, S. 2003. "The information technology outsourcing risk: a transaction cost and agency theory-based perspective," Journal of Information Technology (18:3), pp. 211-221.

Bahli, B., and Rivard, S. 2013. "Cost escalation in information technology outsourcing: A moderated mediation study," Decision Support Systems (56), pp. 37-47.

Bapna, R., Barua, A., Mani, D., and Mehra, A. 2010. "Research Commentary-Cooperation, Coordination, and Governance in Multisourcing: An Agenda for Analytical and Empirical Research," Information Systems Research (21:4), pp. 785-795.

Bunker, D., Hardy, C., Babar, A., and Stevens, K. J. 2016. "Exploring Practitioner Perspectives of Sourcing Risks: Towards the Development of an Integrated Risk and Control Framework," Australasian Conference on Information Systems, Adelaide, South Australia .

Chang, Y. B., Gurbaxani, V., and Ravindran, K. 2017. "Information Technology Outsourcing: Asset Transfer and the Role Of Contract.," MIS Quarterly (41:3), pp. 959-973.

Choi, T. Y., Wu, Z., Ellram, L., and Koka, B. R. 2002. "Supplier-supplier relationships and their implications for buyer-supplier relationships," IEEE transactions on engineering management (49:2), pp. 119-130.

Clemons, E. K., and Hitt, L. M. 2004. "Poaching and the misappropriation of information: Transaction risks of information exchange," Journal of Management Information Systems (21:2), pp. 87107.

Clemons, E. K., Reddi, S. P., and Row, M. C. 1993. "The impact of information technology on the organization of economic activity: The "move to the middle' hypothesis," Journal of management information systems (10:2), pp. 9-35. 
Cohen, L., and Young, A. 2006. Multisourcing: Moving beyond outsourcing to achieve growth and agility, Harvard Business Press.

Crosno, J. L., and Dahlstrom, R. 2008. "A meta-analytic review of opportunism in exchange relationships," Journal of the Academy of Marketing Science (36:2), pp. 191-201.

Cross, J. 1995. "IT outsourcing: British Pertroleum's Competitive Approach," Harvard Business Review.

Cullen, S., Seddon, P. B., and Willcocks, L. P. 2005. "IT outsourcing configuration: Research into defining and designing outsourcing arrangements," The Journal of Strategic Information Systems (14:4), pp. 357-387.

Currie, W. L. 1998. "Using multiple suppliers to mitigate the risk of IT outsourcing at ICI and Wessex Water," Journal of Information Technology (13:3),pp. 169-180.

Currie, W. L., and Willcocks, L. P. 1998. "Analysing four types of IT sourcing decisions in the context of scale, client/supplier interdependency and risk mitigation," Information Systems Journal (8:2), pp. 119-143.

Dibbern, J., Goles, T., Hirschheim, R., and Jayatilaka, B. 2004. "Information systems outsourcing: a survey and analysis of the literature," ACM SIGMIS Database the DATABASE for Advances in Information Systems', (35:4)ACM, pp. 6-102.

Everest. 2018. "Upcoming Contract Renewals-Application services," Everest Group Research, Everest Global, Inc. .

Gefen, D., Wyss, S., and Lichtenstein, Y. 2008. "Business familiarity as risk mitigation in software development outsourcing contracts," MIS quarterly(32:3), pp. 531-551.

Goldberg, M., Kieninger, A., and Fromm, H. 2014. "Organizational models for the multi-sourcing service integration and management function," in Business Informatics (CBI),Geneva, pp. 101-107.

Granovetter, M. 1985. "Economic action and social structure: The problem of embeddedness," American journal of sociology (91:3), pp. 481-510.

Heide, J. B., Kumar, A., and Wathne, K. H. 2014. "Concurrent sourcing, governance mechanisms, and performance outcomes in industrial value chains," Strategic Management Journal (35:8), pp. $1164-1185$.

Huang, R., Miranda, S., and Lee, J.-N. 2004. "How many vendors does it take to change a light bulb? Mitigating the risks of resource dependence in information technology outsourcing," In Proceedings of Twenty-Fifth ICIS, 2004, pp. 311-323.

Jap, S. D., and Anderson, E. 2003. "Safeguarding interorganizational performance and continuity under ex post opportunism,” Management Science (49:12), pp. 1684-1701.

Jones, G. R. 1984. "Task visibility, free riding, and shirking: Explaining the effect of structure and technology on employee behavior," Academy of Management Review (9:4), pp. 684-695.

Kim, D.-Y. 2014. "Understanding supplier structural embeddedness: A social network perspective," Journal of Operations Management (32:5), pp. 219-231.

Koo, Y., Lee, J.-N., Heng, C. S., and Park, J. 2017. "Effect of multi-vendor outsourcing on organizational learning: A social relation perspective," Information\& Management (54:3), pp. 396-413.

Lacity, M. C., Khan, S. A., and Willcocks, L. P. 2009. "A review of the IT outsourcing literature: Insights for practice," The Journal of Strategic Information Systems (18:3), pp. 130-146.

Lacity, M. C., Khan, S. A., and Yan, A. 2016. "Review of the empirical business services sourcing literature: an update and future directions," Journal of Information Technology (31:3), pp. 269328.

Levina, N., and $\mathrm{Su}, \mathrm{N}$. 2008. "Global multisourcing strategy: the emergence of a supplier portfolio in services offshoring,” Decision Sciences (39:3), pp. 541-570.

Lioliou, E., and Zimmermann, A. 2015. "Vendor opportunism in IT outsourcing: a TCE and social capital perspective," Journal of Information Technology (30:4), pp. 307-324.

Loboda, B. 2013. "Motives for Multisourcing in the IT Sector," International Journal of Management and Economics (38:1), pp. 46-66. 
Mahnke, V., Wareham, J., and Bjorn-Andersen, N. 2008. "Offshore middlemen: transnational intermediation in technology sourcing," Journal of Information Technology (23:1), pp. 18-30.

Mathew, S. K., and Chen, Y. 2013. "Achieving offshore software development success: An empirical analysis of risk mitigation through relational norms," The Journal of Strategic Information Systems (22:4), pp. 298-314.

Nooteboom, B., Berger, H., and Noorderhaven, N. G. 1997. "Effects of trust and governance on relational risk," Academy of management journal (40:2), pp. 308-338.

Osarenkhoe, A. 2010. "A study of inter-firm dynamics between competition and cooperation-A coopetition strategy," Journal of Database Marketing \& Customer Strategy Management (17:34), pp. 201-221.

Porter, M. E. 1985. "Competitive advantage: creating and sustaining superior performance. 1985," New York: FreePress (43), p. 214.

Provan, K. G. 1993. "Embeddedness, interdependence, and opportunism in organizational supplierbuyer networks," Journal of Management (19:4), pp. 841-856.

Provan, K. G., and Kenis, P. 2008. "Modes of network governance: Structure, management, and effectiveness," Journal of public administration research and theory (18:2) pp. 229-252.

Ravindran, K., Susarla, A., Mani, D., and Gurbaxani, V. 2015. "Social capital and contract duration in buyer-supplier networks for information technology outsourcing," Information Systems Research (26:2), pp. 379-397.

De Sá-Soares, F., Soares, D., and Arnaud, J. 2014. "Towards a theory of information systems outsourcing risk," Procedia Technology (16), pp. 623-637.

$\mathrm{Su}, \mathrm{N}$., and Levina, N. 2011. "Global multisourcing strategy: Integrating learning from manufacturing into IT service outsourcing," IEEE Transactions on Engineering Management (58:4), pp. 717729.

Susarla, A., Subramanyam, R., and Karhade, P. 2010. "Contractual provisions to mitigate holdup: Evidence from information technology outsourcing," Information Systems Research (21:1), pp. $37-55$.

Tan, C., and Sia, S. K. 2006. "Managing flexibility in outsourcing," Journal of the Association for Information Systems (7:4), pp. 179-206.

Thompson, J. D. 1967. Organizations in action, New York: McGraw-Hill.

Wathne, K. H., and Heide, J. B. 2000. "Opportunism in interfirm relationships: Forms, outcomes, and solutions," Journal of marketing (64:4), pp. 36-51.

Wiener, M., and Saunders, C. 2014. "Forced coopetition in IT multi-sourcing," The Journal of Strategic Information Systems (23:3), pp. 210-225.

Williamson, O. E. 1975. "Markets and hierarchies," New York (2630).

Williamson, O. E. 1985. The Economic Institutions of Capitalism: Firms, markets, relational Contracting, Free Press.

Williamson, O. E. 1993. "Opportunism and its critics," Managerial and decision economics (14:2)Wiley Online Library, pp. 97-107.

Wüllenweber, K., Jahner, S., and Krcmar, H. 2008. "Relational risk mitigation: the relationship approach to mitigating risks in business process outsourcing 2008 41st Annual Hawaii International Conference on System Sciences, 7-10 Jan. 2008," Waikoloa, HI, USA .

Copyright: (C) 2018 Shroff Bandi. This is an open-access article distributed under the terms of the Creative Commons Attribution-NonCommercial 3.0 Australia License, which permits non-commercial use, distribution, and reproduction in any medium, provided the original author and ACIS are credited. 